\title{
Relacionamentos interpessoais e emoções nas organizações: uma visão biológica*
}

\author{
Sergio Proença Leitão** \\ Graziela Fortunato*** \\ Angilberto Sabino de Freitas****
}

S u MÁRIO: 1. Primeiras considerações; 2. Razão e emoção nos relacionamentos: o indissociável; 3. A qualidade dos relacionamentos: fundamentos biológicos; 4 . O caso da economia de comunhão; 5. Conclusão.

SUMMARY: 1. Opening remarks; 2 . Reason and emotion in relationships: the inseparable; 3. The quality of relationships: biological foundations; 4. The case of the communion economy; 5 . Conclusion.

Palavras-CHAVE: qualidade dos relacionamentos interpessoais; emoçãorazão; teoria substantiva; amor-ação.

KEY WORDS: quality of interpersonal relationships; emotion-reason; substantive theory; love-action.

Este artigo questiona o tratamento dado pela teoria organizacional aos relacionamentos interpessoais, por sua forma dominantemente racionalista, instrumental e prescritiva e apenas parcialmente integrada ao seu elemento central: a emoção. Sugere uma nova linha de pesquisa para desenvolver uma teoria substantiva sobre relacionamentos intra e interorganizacionais centrada na emoção do amor, conforme seu conceito biológico. E propõe que a investigação tome como referência a experiência do projeto de economia de comunhão.

* Artigo recebido em maio e aceito em ago 2006.

** Professor associado do IAG/PUC-Rio, doutor em educação e mestre em administração. Endereço: Rua Comendador Francisco Leal, casa 122 - Itanhangá - CEP 22641-180, Rio de Janeiro, RJ, Brasil. E-mail: proenca@iag.puc-rio.br.

*** Doutorando em administração do IAG/PUC-Rio. Endereço: Rua Barão da Torre, 567/802 — Ipanema - CEP 22411-003, Rio de Janeiro, RJ, Brasil. E-mail: grazif@gmail.com.

**** Doutorando em administração do IAG/PUC-Rio. Endereço: Rua Ozório Duque Estrada, 74, ap. 201 - Gávea — CEP 22451-170, Rio de Janeiro, RJ, Brasil. E-mail: angilberto@iag.puc-rio.br. 


\begin{abstract}
Interpersonal relationship and emotion in organizations: a biological perspective

This article discusses the treatment given by the organizational theory to interpersonal relationships, for its dominantly rationalistic, instrumental, and prescriptive form, only partially integrated to its main element: emotion. The article suggests a new line of research for developing a substantive theory of intra and inter-organizational relationships, centered in the emotion of love, according to its biological concept. It also proposes that the investigation use the experience of the communion economy project as a reference.
\end{abstract}

\title{
1. Primeiras considerações
}

A boca fala da abundância do coração.

Mateus, 12:34

A questão dos relacionamentos interpessoais, e de sua inerente dimensão emocional, é crucial para a vida associada, pois são esses processos interativos que formam o conjunto de sistemas que a organizam. As condições em que ocorrem tais relacionamentos definem a forma de convivência entre os seres humanos, que são seres de relações, e destes com a natureza. Fazem a diferença entre sofrimento e bem-estar e definem como a vida social é construída em seu cotidiano. Deteriorações nas relações interpessoais resultam em deterioração das relações sociais, das relações inter e intra-organizacionais.

O sucesso de best-sellers como Inteligência emocional, $O$ monge e o executivo, ou Jesus o maior psicólogo que já existiu está ligado à demanda crescente por conhecimento nessa área. E pode estar indicando que as contribuições teóricas não foram suficientes para orientar gerentes e suas políticas.

A psicologia social, a comportamental e a clínica; a biologia cognitiva; as neurociências em geral; ou as grandes tradições religiosas; sem falar em algumas correntes filosóficas, têm enfatizado sua importância para a vida humana. Todavia não se pode identificar, no campo dos estudos organizacionais, uma "teoria dos relacionamentos", em que as dimensões emocional e ética sejam seus componentes indissociáveis, conferindo-lhe perfil substantivo, nos termos de Guerreiro Ramos (1981:25). Muito do que sabemos sobre relacionamentos interpessoais é inexato e desarmônico para constituir uma teoria confiável e prescrever comportamentos.

Livros conhecidos da teoria organizacional, como os de Charles Handy; Richard Hall; Gibson, Ivancevich e Donnelly; Clegg, Hardy e Nord; Gareth 
Morgan ou Stephen Robbins, não tratam diretamente do tema. Ele aparece implícito no estudo das emoções e em diversas teorias (gupos, papéis, liderança, motivação, conflito, decisão, mudança etc.), ou dissociando o interpessoal do interorganizacional, com enfoque dominantemente instrumental.

Como uma teoria geral, as relações humanas foram tratadas como uma justificativa ideológica da estrutura institucional vigente, voltada para os problemas de ajustamento dos indivíduos e esquivando-se do trato dos conflitos (Motta, 1986:77). Da mesma forma, na escola comportamental, onde o estrutural delimita o comportamento. Em qualquer escola, a instrumentalização domina e as relações interpessoais têm caráter eminentemente técnico.

Nord e Fox (2004:186) observam que a ênfase nos estudos organizacionais, a partir dos anos 1980, vem se deslocando de uma visão do indivíduo, independente de seu contexto, para considerar a interação entre indivíduos e seus contextos; o mesmo deslocamento observado da psicologia cognitiva para a psicologia sociocognitiva. Os dois autores lembram que os trabalhos de Foucault influenciaram diversos autores nessa passagem para uma visão relacional e dinâmica. Passagem que envolve o reconhecimento de que indivíduos são constituídos por meio de domínio social, descobrindo o sociobiológico na vida social, sem esconder seu caráter relacional (Nord e Fox, 2004:200). Mas nada até aí se configura na busca de uma teoria substantiva do relacional.

As recentes contribuições identificadas como teoria dos stakeholders (TS) e o movimento de responsabilidade social corporativa (RSC), com versões instrumentais e normativas, representam um avanço na compreensão das relações interpessoais e interorganizacionais no ambiente empresarial, mais do que a teoria dos custos de transação, as teorias das relações intergrupais incrustradas, a teoria do agente, ou a teoria das partes interessadas do Stanford Research Institute dos anos 1960. Mas há ainda limitações em todas elas.

Aquele grupo de contribuições, da TS e da RSC, ainda é criticado, quanto à sua validade teórica e aos seus fins, por diversos teóricos das organizações e pela ortodoxia capitalista, que assume posição antagônica à perspectiva de Polanyi (2000:60), quando este afirma que a economia do homem, como regra, está submersa em suas relações sociais. Ainda hoje, para os muitos seguidores de Milton Friedman, a única responsabilidade das empresas é para com seus acionistas.

Questões ideológicas à parte, o que mais importa é que aquele conjunto de contribuições trata de relacionamentos econômicos, desprezando outros aspectos da vida humana e se preocupando com riscos, com a sobrevivência imediata da empresa, mapeando os interesses econômicos da organização. Mesmo em algumas de suas versões éticas, preocupadas com a dignidade humana e implicações socioambientais, o emocional do relacionar está ali desconectado. 
Entender a interação emoção-razão, demonstrada pela neurofisiologia, exige reexaminar o pressuposto da racionalidade limitada, assumido por aquele conjunto de teorias.

A corrente normativa da teoria dos stakeholders, de orientação substantiva, considera indivíduos e grupos mais do que simples entidades maximizadoras de lucros; são um fim em si mesmos, devendo todos os processos administrativos respeitar sua dignidade. Essas variadas contribuições, que incluem os trabalhos de Kewin Gibson, Quinn e Jones, Virginia Gerde, Harry Hummels, Chryssides e Kaler, Bruce Langtry, Simon Zadek e outros (Pinto e Leitão, 2006:28), não estão atentas à natureza dos relacionamentos interpessoais e ao papel central que a emoção representa neles. Mesmo o ético está nelas desligado do emocional, pois seguem a tradição racionalista, oriunda do iluminismo, são objetivistas e não penetram mais fundo na identificação de sua qualidade. Até porque sua força relacional visa, pragmaticamente, a força mercadológica, deixando vazios teóricos na compreensão da natureza desses relacionamentos e da natureza de seu conhecimento. A teoria dos stakeholders não foi capaz de responder à questão de Henriquez (1997) quanto aos motivos que tornaram a perversão a forma privilegiada dos relacionamentos humanos em uma sociedade que instrumentaliza seus indivíduos. A história do capitalismo é de deterioração das relações e a razão que tornou hegemônico o capital, sufocou a dimensão emocional da vida.

As práticas das empresas do projeto de economia de comunhão (EdC), de orientação espiritual-cristã, parecem estar fornecendo dados mais relevantes para a compreensão do que seja qualidade de relacionamento humano do que as teorias da chamada "ciência normal". Sobretudo quanto à contribuição para induzir as mudanças necessárias para enfrentar a crise socioambiental instalada no planeta. O estudo de Pinto (2004) identificou nas ações de EdC, representadas por suas empresas líderes, proximidade com as fundamentações da TS e da RSC, pois ambas carregam uma visceral preocupação com as condições atuais do planeta e procuram emparelhar ética e competitividade. Mas constatou também que não existe uma completa superposição entre a experiência de EdC e aquelas contribuições teóricas. A diferença mais relevante está naquilo que em economia de comunhão fundamenta a qualidade de seus relacionamentos, o que aquele conjunto de contribuições não foi capaz de ver.

$\mathrm{O}$ trato dos relacionamentos interpessoais de maneira instrumental, como forma de dominação sobre o trabalho, gera resultados limitados e perversos, tanto ao bem-estar no trabalho, quanto à produtividade. O que as empresas de EdC estão sugerindo, e também outras experiências empresariais, é que para haver aumento espontâneo da produtividade do trabalho é preciso elevar o nível de qualidade nos relacionamentos entre todos que operam a empresa. 
Mais do que isso, humanizar a empresa pode significar aumento da sua capacidade de sobrevivência e a do próprio planeta, pois as empresas têm grande responsabilidade sobre a crise socioambiental que vivemos.

No que até agora foi feito sobre esses temas interdependentes, relacionamentos interpessoais e relacionamentos interorganizacionais, nas muitas contribuições daquilo que se denominou teoria dos stakeholders e responsabilidade social corporativa, há mais prescrição do que descrição ou explicação e, menos ainda, compreensão da importância desses conceitos para a gestão de empresas. O que aquelas duas correntes têm em comum é a idéia de fazer negócios com sustentabilidade e ética, apesar de não terem ainda definições universalmente aceitas (Pinto e Leitão, 2006:40).

Talvez seja mais produtivo retomar a pesquisa básica sobre esses conceitos interligados, para desenvolver uma teoria dos relacionamentos na administração de empresas, com mais coerência teórica, evidência empírica, viabilidade e conhecimento de suas implicações, a partir da experiência das empresas do projeto de EdC e de outras de orientação substantiva. Para tanto será necessário reexaminar a natureza do fenômeno relacionamento e a natureza de seu conhecimento, mas em bases interdisciplinares. Precisamos entender "o que é" esse fenômeno.

Também precisamos de pesquisas para entender o "como é" e não tanto o "como deve ser" pois, como dizem Ann Tenbrunsel e seus associados, os estudos sobre o comportamento vêm enfatizando a importância da participação, cooperação, coletivismo ou empowerment, antes de alcançar suficiente embasamento empírico (2004:34). Os modelos prescritivos precisam incorporar o conhecimento descritivo para serem mais eficazes.

Insistindo nesse ponto, trazido por Trenbrunsel, se as pessoas não são maximizadores racionais, como pressupõem os economistas liberais, precisamos entender a maneira pela qual nos afastamos da racionalidade. Assumindo que as decisões são fundamentais, tanto para entender quanto para mudar comportamentos em organizações, ou ainda, assumindo que grande parte do conhecimento organizacional que orienta as decisões provém de processos interativos, então devemos conhecer mais profundamente como e até onde os relacionamentos interpessoais podem explicar o comportamento na empresa. Está implícito aqui que adquirimos conhecimento e seu conjunto de significados, uns com os outros, como explica a biologia cognitiva e o sociocognitivismo (Levine et al., 1993).

Este artigo, ao valorizar a dimensão comunitária das organizações produtoras, introduz essa proposta, questionando o tratamento dado pelos estudos organizacionais ao tema, particularmente no trato dado às emoções, e revendo a experiência das empresas de economia de comunhão, conforme re- 
latos de seus pesquisadores. Lança mão de conceitos introduzidos pela biologia do conhecimento em sua linha de argumentação, para propor novas bases conceituais e justificar a relevância do tema.

Apóia-se no projeto de EdC, porque aquelas empresas de pequeno e médio portes parecem estar demonstrando que a busca espontânea de legitimação social, responsabilidade pública e discrição gerencial, nas esferas legal e ética, trabalhando simultaneamente as dimensões espiritual, racional e emocional humanas, pode levar à eliminação ou substancial redução da deterioração dos relacionamentos no trabalho. Na realidade, parecem adotar formas de relacionamento que induzem a mudanças na racionalidade e nas práticas de mercado, sem negá-lo. Os estudos de campo sobre tais empresas (Brandalise, 2003; Pinto, 2004; Gonçalves, 2005; Leitão e Kurtz, 2005; Machado, 2006) mostram tais relacionamentos como seu grande diferencial competitivo e sugerem maior aptidão para lidar com mudanças transformadoras e com a aprendizagem que tais mudanças requerem.

Elas são o que se poderia chamar "empresas de mudança", já que estão conseguindo romper com os parâmetros daquilo que Guerreiro Ramos (1981:86) denominou "política cognitiva centrada no mercado". Com políticas de pessoal não manipulativas ou instrumentalizadoras da pessoa humana, tratando-a mais como aprendizes cooperativos do que como conhecedores individuais, elas vêm, desde 1991, quando começou o projeto, obtendo resultados econômico-financeiros satisfatórios, além de indicar, por parte de seus patrões e empregados, maior grau de satisfação com o trabalho. Nelas pouco se encontra do mal-estar comum à maioria das empresas públicas e privadas.

Participação, partilha, diálogo, cooperação e solidariedade são as palavras-chave que conferem qualidade aos relacionamentos desenvolvidos na empresas mais avançadas no projeto (Almeida e Leitão, 2003). Mas a fonte geradora dessas características relacionais está no que Humberto Maturana (2001:31) considera o elemento fundamental à viabilização da vida associada: a aceitação do outro como um ser legítimo na convivência. Esse neurobiólogo e filósofo, fundador da escola de Santiago e um dos pais da teoria dos sistemas vivos, que tem suas bases teóricas na neurobiologia e na cibernética de segunda ordem, origem da biologia cognitiva (Behncke, 1995:36), considera que esse princípio comportamental básico corresponde ao conceito cristão de amor. O conceito é tratado como a emoção primordial do comportamento humano, lembrando que os biólogos dessa escola consideram a competição como fenômeno cultural e a cooperação como fenômeno biológico presentes em todas as espécies (Maturana e Varela, 1995; Maturana e Bunnell, 1998; Maturana, 1995 e 2001). 


\section{Razão e emoção nos relacionamentos: o indissociável}

A importância dada aos relacionamentos parte do pressuposto de que as necessidades e interesses das organizações são as necessidades e interesses dos indivíduos de forma coletiva. Suas necessidades se originam no ser complexo que somos e que, necessariamente, passam pela emocionalidade das relações sociais e suas trocas intersubjetivas.

Para a biologia cognitiva, emoção refere-se ao domínio de ações em que um ser animal se move; às ações possíveis do outro, seja ele um animal ou uma pessoa (Maturana, 2001:22). Assim, não existe ação humana sem uma emoção que a estabeleça como tal e a torne possível como ato. Maturana afirma que não é a razão que nos leva à ação, mas a emoção. E a emoção fundamental que torna possível a história da hominização é o amor, sem preocupação com a visão cristã desse termo, mas sim com algo que é constitutivo da vida e fundamento da vida associada. Nesta, nos comportamos pelo sentir/pensar/agir e não apenas pelo pensar/agir como pressupõe o racionalismo.

Nesse sentido, o amor é a emoção que constitui o domínio de condutas em que se dá a operacionalidade da aceitação do outro como ser legítimo no convívio social. E tal base biológica da relação, que tem fortes implicações com o uso da palavra e do diálogo, não pode ser afastada da natureza dos relacionamentos humanos e de suas vinculações com o que é social. Tal perspectiva tem conseqüências para a compreensão do papel das emoções nas relações de trabalho, até hoje área de dissenso na pesquisa em organizações, depois de mais de um século de crescente dissociação entre razão e emoção, ignorando sua complementaridade.

As principais contribuições ao conhecimento das emoções, no âmbito da administração de empresas, vieram da psicologia comportamental e da psicologia clínica a partir dos anos 1940, tratadas em termos de sentimentos, humor, moral, pertencimento a grupos ou comprometimento com tarefas, como lembra Fineman (2000:158). De 1950 a 1970 o tema aparece em estudos sobre atitudes, principalmente quanto à satisfação no trabalho, e nos anos 1970 retoma-se o enfoque cognitivo do comportamento humano em termos de expectativas, informação e solução de problemas, com ênfase nas emoções ditas positivas.

Os primeiros esforços para unificar cognição (razão) e emoção surgem nos anos 1980 e 1990, mais voltados para a avaliação de desempenho e estudo da decisão (Fineman, 2000:159). É nesse período que começam a ser divulgadas pesquisas no campo das neurociências, particularmente da neurofisiologia, mostrando a interdependência entre razão e emoção no operar do cérebro hu- 
mano, mas que pouco penetraram a teoria organizacional, para desmantelar de vez a idéia de que somos maximizadores racionais de utilidade.

A emoção penetra o ambiente organizacional associada à constituição das tarefas, preocupada, em última instância, com o desempenho lucrativo, seguindo a crença estabelecida pela força do racionalismo de que a ordem organizacional e a eficiência das relações entre gerentes e trabalhadores devem ser tratadas racionalmente. Em suma, "boas" organizações são as que têm emoções gerenciadas e a teoria organizacional deveria se preocupar mais com processos cognitivos e controle comportamental. Um viés problemático à pesquisa.

Recentemente começaram a surgir estudos sobre a influência da organização e das relações interpessoais no comprometimento afetivo em empresas, como o estudo de Hui, Lee e Rousseau (2004) em empresas chinesas, com temas para correlacionar às emoções muito variados. Como são variadas as escolhas temáticas em outros autores.

Geralis e Terziouski (2003) descobriram que dar poder aos indivíduos gera emoções positivas com imediata repercussão sobre a motivação para o trabalho, a qualidade dos serviços e os resultados operacionais. O estudo de Calahan (2002) relaciona gestão com comportamento emocional e suas implicações para a mudança cultural. Mayer, Caruso e Salovey (1999) tomam o conceito de inteligência emocional para associá-lo a um conjunto de habilidades cognitivo-afetivas que as pessoas usam para administrar suas emoções. Conceito também utilizado por Wong e Law (2002), relacionado ao estudo da liderança e avaliação de desempenho. Mas o emocional é percebido como sentimento e não como impulsionador da ação, como na visão biológica.

Linha similar foi seguida por Cavallo (2002), na Johnson \& Johnson, para verificar competências específicas em líderes que os caracterizem como de alto ou baixo desempenho, concluindo que os líderes de alto desempenho são os de mais alta competência emocional. Offermann e co-autores (2004) também trabalharam com o conceito de competência emocional e habilidade cognitiva para verificar suas implicações no desempenho de grupos, atitudes e percepções das lideranças. E Ashkanasy e Daus (2002) visualizaram o gerenciamento das emoções como uma importante ferramenta no kit de trabalho de um gerente, pois as mais simples e mundanas emoções devem ser "administradas".

Podem ainda ser lembrados os modelos prescritivos de Wilson e colaboradores (2004), Rafaeli e Sutton (1987), os de Rejun e Zigang (2005) e de Hui e co-autores (2004), ou de Kelly e Barsade (2001) cuja modelização mistura interações entre fatores afetivos e não afetivos.

Tais contribuições, no entanto, apresentam um quadro dominante: são racionalistas, instrumentais-objetivas, fortemente quantitativas e prescritivas, se- 
guindo a maneira funcional-positivista de ver. E como lembram Nord e Fox (2004:205) o indivíduo tem aí um papel preponderante, de forma semelhante aos estudos anteriores sobre satisfação e atitudes no trabalho. Remetendo ao psicólogo Edward Sampson, eles observam que o individualismo foi sempre tratado como um evento sócio-histórico e não como um evento natural, seguindo os pressupostos do individualismo liberal.

Na maioria dos estudos, os relacionamentos interpessoais aparecem de forma implícita; a integração relacionar-emocionar não tem vínculo ontológico. Os relacionamentos emergem quando esses estudos assumem que as emoções são primordialmente reações individuais causadas por interações sociais e são vistas como fenômenos sociais (Rejun e Zigang, 2005). Emoções surgem, então, como reações a relacionamentos em um processo interativo de influência mútua e não omitem a influência da cultura organizacional ou de processos comunicativos. Emoções são aí freqüentemente visualizadas como conseqüências do que os outros dizem ou fazem, por outros entendemos indivíduos ou normas.

A literatura sobre emoções e organizações apoiou-se sempre na essencialidade do indivíduo e só recentemente vem se voltando para o contextual, para o que é relacional. Pressupõe, portanto, papel relevante ao uso da palavra e dos significados que elas podem alcançar, no diálogo, embora isso nem sempre esteja explícito nesses estudos, pois a busca da linearidade e simplificação acaba excluindo os múltiplos elementos que enriquecem um processo complexo.

Rejun e Zigang (2005) reconhecem que as emoções se contextualizam no campo das relações interpessoais, por meio de um processo de ações e reações entre pessoas. Tal visão coloca o locus das emoções nas relações interpessoais, mas não explicita a quem cabe a iniciativa da ação, à emoção ou à razão, o que faz diferença para a compreensão do comportamento humano. A maior parte do tempo investido em pesquisas sobre o tema não foi para descrever esse locus e sim para associar ou correlacionar emoções com cultura, comunicação, conhecimento, motivação, liderança, aprendizagem e mudança. Um comportamento emocional reificado e examinado por meio de associações binárias constituem as abordagens dominantes.

Vários desses estudos deixaram a descoberto suas limitações quanto à compreensão desse fenômeno biopsicoantropossocial, suas múltiplas dimensões e implicações para a vida organizacional. São variadas as definições de emoção, de sentimento e para o significado de satisfação no trabalho. Weiss (2002) lembra que tais distinções são comuns na literatura e mostra como modelos racionais sobre emoções - a objetivação do subjetivo - sugerem visões distorcidas. 
As críticas são também diversas, vindas de dentro ou de fora da corrente dominante. Lucas, Diener e Suh (1996) afirmam que os julgamentos de satisfação medidos pelos níveis de experiências negativas e positivas não foram bem-sucedidos, pois tais fatores são muito subjetivos para permitir modelização. Por outro lado, as emoções foram traduzidas em formas organizacionais aceitáveis e sua expressão pode gerar produtos organizacionais positivos, mas também criar um "torpor emocional", como dizem Maanen e Kunda (1989). Críticas como as de Mumby e Putnam (1992), Conrad e Witte (1984) indicam outras dificuldades em lidar com o tema. Albrow (1997) observa que faltou maior compreensão do sentir-pensar-agir nas organizações, considerando a natureza contingencial, heterogênea e fragmentária dos processos sociais.

Na expressão de Morin (1999:153) o tema é mais acessível às abordagens analógico-subjetivas (compreensão) do que às lógico-objetivas (explicação) usadas naqueles estudos, pois estas não entendem o que é subjetivo. De forma mais elementar, Jahn e Dune (1997) lembram que o objetivo é a moeda dos processos de informação utilizada para transmitir conhecimento impessoal, quantitativo, próprio a dígitos binários, enquanto o subjetivo transmite valores, significados e perspectivas não valorados naquela moeda.

Assim se justificam as críticas aos estudos sobre emoções nas empresas direcionadas por abordagens racionalistas, sobretudo as centradas em modelagem e indicadores de desempenho, objetivando prescrever comportamentos "administráveis". Dito de outra maneira por Behncke (1995:17):

\begin{abstract}
Não é possível conhecer objetivamente fenômenos sociais nos quais o próprio observador-pesquisador está envolvido... Essa noção do "conhecer" bloqueou firmemente a passagem do conhecimento humano para a compreensão de seus próprios fenômenos sociais, mentais e culturais.
\end{abstract}

A questão metodológica é, na realidade, crucial para a compreensão dos relacionamentos interpessoais, levando os biólogos Francisco Varela, Jonathan Shear e outros a um esforço para construir as bases de uma ciência da consciência que inclua a experiência subjetiva como componente ativo e explícito nas relações humanas.

A questão epistemológica transparece no tratamento dado à natureza das emoções no contexto organizacional. A previsível dominância do racionalismo, autêntico mito modernista, cria bloqueios e vieses inibidores do acesso à ontologia desse fenômeno humano e a seu caráter multirrelacional e interdisciplinar. Os limites impostos pelo paradigma dominante, a força do cognitivismo, as prisões ideológicas e psicológicas do sentir-pensar, se associam para dificultar a penetração no denso mundo da subjetividade humana. A emoção 
sempre foi afastada do aprendizado escolar e universitário, despreparando, desde cedo, os futuros cientistas para lidar com sua investigação. A demonização das emoções como sentimentos acabou por inibir sua compreensão como comportamento, inclusive a emoção amorosa, fundamental à integração humana em toda atividade social.

O modernismo vem tratando os relacionamentos como se fossem coisas, concebendo o que é processo de uma forma linear, discreta e fragmentada. Por meio de uma racionalidade instrumental crescente vê a administração de empresas preocupada com controle e colonização progressiva das pessoas e do ambiente natural (Alvesson e Deetz, 1999). Vem pontuando os relacionamentos, para reduzir a complexidade da rede de relações e torná-los mais gerenciáveis. Mas, para compreender o papel dos relacionamentos entre pessoas é preciso privilegiar a dinâmica do processo, as micropráticas organizacionais, com o que a maioria dos pesquisadores tem dificuldade ou rejeita lidar metodologicamente. Precisamos ainda apreender a organização de nosso pensamento não apenas em sua lógica, mas também no seu emocional, buscando conhecimento nas neurociências.

O problema das relações sociais aparece de forma crítica no marxismo, na teoria crítica e nos pensadores pós-modernos, mas nenhuma dessas correntes foi capaz de libertar-se dos limites impostos pelo racionalismo. Apesar de sua preocupação substantiva com o pensar ético, esses críticos não perceberam o vínculo com as emoções, apontado posteriormente por neurocientistas e pela biologia cognitiva (Maturana, 2001:74).

Tais limites epistêmicos e metodológicos têm dificultado compreender, de forma analógico-subjetiva (Morin, 1999:154), as influências mútuas dos relacionamentos interpessoais, interorganizacionais e sociais. O poder dos relacionamentos interpessoais para influir nos processos e estruturas organizacionais permanece fragmentado, visto como algo estático e separado da experiência humana, que é também subjetiva, pois envolve a relação consciência-inconsciência em nossos atos, relação denunciada na obra de Freud.

Nos estudos organizacionais, a racionalidade sistêmica e sua proposta de integração pareciam ter vindo para colaborar com essa dimensão comunitária da vida organizacional, mas sua visão das empresas como sistemas, subsistemas e supersistemas, não só disfarçou as relações de poder, como ignorou as pessoas, tratadas como funções. Tratou de relações entre funções. As visões estrutural e funcionalista também estiveram mais preocupadas em favorecer a diretividade e a manipulação, dominadas por uma lógica econômica e técnica, recusando penetrar a dimensão substantiva e emocional da vida associada, vital para o entendimento da mudança. 
Os estudos organizacionais desenvolveram uma visão ordenada do mundo empresarial, assumindo a realidade administrativa como racional, controlável e passível de uniformização. Em seu conjunto, a teoria organizacional, na ânsia de oferecer soluções, descuidou-se do essencial de seus problemas: as condições do homem no ambiente de trabalho e suas implicações sociais. Mais preocupada com a visão do capital, levou à conjugação de produtividade com destrutividade e opressão. É inevitável lembrar a conhecida crítica de Prestes Motta (1986:109). Ou a crítica de Guerreiro Ramos (1981:33) sobre a visão sociomórfica do homem na TO, que o reduz a um ser economicamente motivado e toma o mercado como categoria fundamental para desenhar e comparar sistemas sociais. Ou ainda, quando aponta um indivíduo preocupado com sua autopreservação, de interesses imediatos e práticos, os seus pontos de referência básicos para o relacionamento com os outros, ou seja, uma visão fortemente instrumental da relação. Diz ele que a organização econômica formal não permite relacionamentos interpessoais livres de pressão e a principal é, certamente, a exercida por aquilo que denominou política cognitiva centrada no mercado, como se esta fosse uma viseira compressora do cérebro humano.

Tal visão do relacionar substitui o padrão ético inerente a uma teoria organizacional substantiva, o objetivo de Guerreiro Ramos em sua obra. E também tornaria difícil pensar numa teoria dos relacionamentos na administração de viés substantivo, ou seja, de natureza ética e crítica, que envolvesse um ser humano dotado de razão, emoção e espiritualidade. Uma teoria que não separasse valores de fatos, pois só uma teoria substantiva poderia levar à compreensão do homem nas variedades históricas de sua condição que é biopsicoantropossocial e não apenas econômica e técnica. Em uma perspectiva substantiva, o objeto central da teoria deveria estar na qualidade dos relacionamentos intra e interorganizacionais, qualidade definida aqui como o relacionamento em que um indivíduo reconhece o outro como legítimo outro na relação, com as implicações daí decorrentes para a vida das pessoas e das organizações. Conceito que tem claras implicações éticas.

Na perspectiva biológica, ética e emoção estão associadas. Isso porque a ética, como preocupação com as conseqüências que nossas ações têm sobre os outros, é um fenômeno relacionado à aceitação do outro e pertence ao domínio da emoção amor. Significa, então, que ela abre um espaço de interações recorrentes com o outro, cuja presença é legítima e sem exigências. E por isso, a postura ética nunca ultrapassa o domínio do social no qual ela surge e, nesse sentido, a ética não tem fundamento racional, mas emocional, diz Maturana (2001:73).

Como decorrência desse postulado da escola de Santiago, a forma de pensar substantiva tem vínculos imediatos com o emocional. E uma teoria subs- 
tantiva dos relacionamentos, obrigatoriamente teria de incluir uma visão da emoção inerente a nossa humanidade. Curioso é que toda a histórica dificuldade com trato da emoção na academia não é comum ao meio empresarial. No estudo de Leitão (2003), sobre a decisão estratégica, a rejeição à presença do emocional no processo de decidir foi de apenas $10,2 \%$.

\section{A qualidade dos relacionamentos: fundamentos biológicos}

O conceito de qualidade de relacionamento interpessoal aqui adotado rejeita automaticamente os comportamentos dos sistemas mecanicistas de gestão que assumem relacionamentos rígidos, baseados na autoridade com obediência, com origem no paradigma militar-taylorista. Um tipo de relacionamento que faz Maturana (2001:69) distinguir relações sociais de não sociais, incluindo as relações de trabalho nesta última categoria, pois se fundam no compromisso de cumprir tarefas, aquilo que realmente importa para o gestor. Razão pela qual tais relações precisam ser reguladas por contratos e normas. $O$ fato de as pessoas terem outras dimensões relacionais não tem maior pertinência nas relações de trabalho. Mas as empresas onde existe maior qualidade nos relacionamentos interpessoais são as que menos recorrem aos sistemas legais, como é o caso das empresas de economia de comunhão (Pinto e Leitão, 2006).

Nessa visão, relações hierárquicas e de poder não são relações sociais e os seres humanos não são todo o tempo seres sociais. Só o somos na dinâmica das relações de aceitação mútua. Com tal sentido, as relações de poder e as formas economicistas e tecnicistas de ver o trabalho obliteram as relações sociais. E isto tem implicações no psiquismo e no bem-estar das pessoas, além de dificultar todo tipo de trabalho grupal, onde as dificuldades de interação prejudicam seus resultados.

É uma visão biológica, mas que lembra o teórico crítico Erich Fromm, em suas obras dos anos 1960, quando apontava o crescente afastamento do ser humano de sua condição natural nas sociedades urbano-industriais, por ele construídas. O que Maturana retoma, quando se refere às nossas criações culturais afastadas de nossa natureza biológica.

Assume-se aqui, portanto, que a hipertrofia - e a enfatizamos - de um pensar instrumental, econômico e técnico acaba por reduzir as demais características humanas, tornando o indivíduo mais competitivo que cooperativo e mais individualista do que coletivista. Além de reduzir o que é reflexivo e ético, com imagináveis conseqüências para a qualidade dos relacionamentos intra e interorganizacionais. 
Para a escola de Santiago, a cooperação entre os participantes de sistemas sociais é sua característica fundamental, envolvendo também aí a capacidade de altruísmo biológico, inerente a todo animal; enquanto o individualismo competitivo é criação da cultura liberal. O que implica na possibilidade de mudança, apesar das conhecidas dificuldades de tais processos. Mudança para retomada das características naturais do ser humano.

Dos sistemas mais simples aos mais complexos, as relações entre indivíduos são interações cooperativas, diretas ou indiretas, ou não seria possível a sobrevivência dos sistemas sociais. Isso leva os biólogos do conhecimento, dessa emergente ciência cognitiva, a afirmar que sem cooperação não pode haver sistema social. Rolf Behncke, no prefácio de $A$ árvore do conhecimento, de Maturana e Varela, diz que desenvolver o conhecimento que possibilita a convivência humana é o nosso maior e mais urgente desafio. A cultura criada em nossas sociedades atenta contra a plena realização do altruísmo natural.

Temos que compreender o tipo de ambiência biopsicoantropossocial que torna a vida associada, em particular, a organizacional, mais ou menos cooperativa. E, como já observado, o domínio das ações (cooperativas ou não) depende do tipo de emoção presente nas relações interpessoais de dado ambiente. Lembre-se que a aceitação do outro tem sua fonte no emocional, mas também se desenvolve no âmbito da razão, pois assim é que interagem o sistema límbico (emoção) e o neocórtex (razão) de nosso cérebro: uma estrutura neurocognitiva de partes indissociáveis e complementares no seu operar, onde o sistema límbico é o mais ágil, colocando a emoção à frente da razão nas respostas ao ambiente.

Maturana (2001:51) esclarece que a aceitação apriorística das premissas que constituem um domínio racional pertence ao domínio da emoção e não da razão. Logo, todo sistema racional tem um fundamento emocional, o que a ortodoxia positivista-cartesiana ignora. O modernismo tem apresentado o homem como um ser racional, como se isso tivesse um fundamento transcendente de validade universal, independentemente do que fazemos como seres vivos. Mas todo sistema racional se baseia em premissas aceitas, porque as preferimos, gostamos delas. Essa denúncia da Eescola de Santiago tem implicações imediatas para a condução da pesquisa no âmbito do humano-social, mas permanece marginalizada dada a força da ortodoxia racionalista. E indica que precisamos estudar a qualidade dos relacionamentos na empresa, a partir da tríplice conexão emoção-razão-ação, onde a emoção é o ponto de partida. É preciso assumir o pressuposto de que o emocional define o caminho do racional, abandonando o pressuposto dominante de que a razão deve afastar a emoção e levar isso para o desenvolvimento de novas metodologias de pesquisa. 
Os relacionamentos, por meio de interações recorrentes, no seio dos grupos humanos é um processo vital na existência e sobrevivência das organizações sociais. Maturana e Bunnell (1998) lembram que a humanidade começou junto com a linguagem e é ela que possibilita a comunicação, mas a linguagem não é algo puramente abstrato, pertence ao espaço concreto dos afazeres. São as conversas sobre os afazeres que propiciam espaço para mudálos e o aparecimento de novos afazeres, possibilitando a mudança organizacional. Seria elementar tal lembrança se não ocorressem até hoje tantas limitações ao uso da linguagem, da conversação nas empresas, como vêm martelando autores da linha humanista. É a linguagem, dizem os dois biólogos, que permite a reflexão e esta a responsabilidade.

A corrente humanista da gestão tem enfatizado o papel da linguagem, da argumentação ou da gestualidade, para mostrar um novo ângulo dos processos comunicativos e fugir à visão mecanicista com que o funcionalismo tratou a questão. Mas isso não foi incorporado a uma teoria de relacionamentos, ateve-se ao exame pontual desse elemento central no processo. Aqueles autores também não penetraram o que Maturana e Bunnell (1998) consideram peculiar ao ser humano e é também central às relações humanas: o amor em seu sentido comportamental, que significa aceitar o outro como ser legítimo, sem ter de concordar com o que diz ou faz, ou ter de gostar dele. Para o cristianismo, coincidentemente ou não, esse é o significado da palavra grega agape usada por Cristo em suas falas aos discípulos.

Tal emoção, segundo aqueles autores, estabiliza os relacionamentos, expande o comportamento inteligente e a criatividade, além de abrir espaço de interações recorrentes com os outros. Já emoções como o medo ou a rejeição, comuns nas culturas autoritárias, restringem nossa capacidade de ver e dialogar, não disponibilizando todo nosso conhecimento, além de restringir a criatividade. A conversação surge aí como o entrelaçamento entre a linguagem e a emoção. Então, toda cultura empresarial que restrinja esse amor-ação inibe a convivência produtiva.

A confrontação dessa perspectiva com as culturas encontradas em muitas de nossas organizações possibilita uma reflexão crítica quanto às condições relacionais no trabalho, o que já vem sendo mostrado pela corrente humanista, embora sem recurso aos fundamentos biológicos e mais próxima a uma perspectiva filosófica marxista do ser humano.

Outra decorrência dessa nova perspectiva, quanto à qualidade dos relacionamentos, está em como se exerce o poder. Como ele surge da emoção da obediência, onde não existe colaboração espontânea, só possível quando a relação se baseia na aceitação legítima da coexistência, tais formas de relacionamento não viabilizam a co-inspiração, que abre espaço psicológico também à 
conversação e à amizade, com implicações para o ambiente favorável ao trabalho grupal. A democratização das relações tem implicações diretas sobre a qualidade dos relacionamentos no trabalho e envolve o problema da liberdade.

Maturana e Bunnell (1998) dizem que autoridade e obediência dão origem à irresponsabilidade e que liberdade é a experiência responsável por sua própria responsabilidade. Nessa concepção, a liberdade não tem a ver com possibilidades, mas como as vivemos.

Uma questão primordial nessa linha de argumentação biológica é que seres humanos se tornam humanos a partir de sua convivência com os outros humanos, das interações ocorridas em seu processo de socialização, ou seja, surgimos e nos desenvolvemos a partir de relacionamentos. Descobrimos nossa existência na existência do outro, dizem aqueles biólogos.

Para a biologia somos seres estruturalmente determinados, mas não predeterminados, nossa constituição genética define um ponto de partida, mas o que vamos ser depende de um padrão emergente e tem a ver com a cultura em que nos criamos. ${ }^{1}$

Por isso afirmamos anteriormente sermos seres de relações, pois elas estão na formação de nossa identidade. E qualquer forma de associação humana que atente contra nossa identidade, dificultando a convivência, é fonte de mal-estar. Razão pela qual vivemos, historicamente, procurando macro e microssistemas que facilitem a convivência: uma busca crescentemente dificultada pela instrumentalização de todas as dimensões da vida.

Nessa busca transitamos entre amor e agressão, concorrência e cooperação, apropriação e partilha, autoritarismo e autonomia, num emaranhado de contribuições vindas das ciências humano-sociais. A biologia cognitiva é mais uma, vinda da ciência natural, e sua força maior está em recuperar nossa esquecida natureza biológica.

Ao dizer que as emoções especificam os tipos de comportamentos relacionais e que o amor é a única emoção que expande o comportamento inteligente, a criatividade e recupera nossa autonomia, liberdade e responsabilidade, Maturana e Bunnell (1998) dizem também que a história da transformação da Shell, multinacional petrolífera, é uma história de amor. Ali as mudanças não teriam ocorrido por meio de luta, competição ou autoritarismo, mas — como em outros casos de mudanças bem-sucedidas - ocorreram sob o domínio dessa emoção (ação) criativa. Entendem que esse seria o caminho duradouro de

\footnotetext{
${ }^{1}$ O desenvolvimento da vida é explicado por Maturana e Varela por meio dos processos de autopoiese, envolvendo os conceitos de ontongenia, epigênese e deriva natural, que constituem o corpo do livro $A$ árvore do conhecimento. 
empresas bem-sucedidas, o caminho para afastar o medo, a desconfiança e a insegurança existentes na vida organizacional. Em suma, esses biólogos da escola de Santiago estão desconstruindo o racionalismo que assumiu o caráter de ideologia na sociedade moderna.

\section{O caso da economia de comunhão}

Qualquer iniciativa teórica que busque identificar a ontologia e a epistemologia dos relacionamentos para orientar a gestão, precisará rever as crenças racionalistas sobre o papel das emoções. Será necessário romper com os pressupostos de conhecimento que operam como princípios inconscientes organizadores de nossa maneira de ver as coisas que nos cercam. Implica em mudança, o que requer conhecer a maneira pela qual conhecemos a vida organizacional, ou seja, uma aprendizagem de segunda ordem, nos termos do biólogo e antropólogo inglês, Gregory Bateson (Foester, 1996:59).

Implica também em refletir sobre a passagem da concepção de emoçãosentimento para a de emoção-ação, reconstruindo a percepção fragmentada que temos da dimensão emocional na vida em organizações. Requer romper com o passado cartesiano, percebendo que o objetivismo não permite entender a natureza dessa questão.

O PhD em psicologia, Mark Baker, diretor da clínica La Vie Counseling Center, na Califórnia, autor do best-seller Jesus o maior psicólogo que já existiu, procurando mostrar pontos comuns entre a psicologia clínica e os evangelhos, afirma que a saúde psicológica requer o reconhecimento de nossas necessidades nos outros e que só nos sentimos ligados aos outros quando compartilhamos experiências emocionais. Como psicólogo clínico, aprendeu que nossas divergências mais sérias não são a respeito do que pensamos, mas resultado de feridas emocionais. Isso é compatível com a visão biológica de Maturana (2001:51), quando diz que somos seres emocionais e utilizamos a razão para justificar as emoções que nos levam à ação. Também tem um ponto de encontro com o pesquisador em epistemologia, Edgar Morin (2003:167), quando este afirma que a razão fechada é simplificadora, enquanto a razão complexa vê a complementaridade entre inteligência e afetividade, entre razão e desrazão, ao propor a busca de uma razão complexa nas ciências.

O sucesso, expresso nas vendas de centenas de milhares dos livros citados no início deste artigo, livros de ajuda pessoal, repulsivos à academia, está em que o senso comum aceita aquele conjunto de argumentos envolvendo nossa dimensão emocional nas relações sociais. Tal tema é central na doutrina cristã, igualmente distante de aceitação pela academia (salvo em seus cursos de 
teologia). Mas a academia ainda não conseguiu explicar e compreender, apenas de forma limitada, sua importância na vida das organizações.

Relacionamentos interpessoais e interorganizacionais são tidos como o grande diferencial das empresas do projeto de economia de comunhão (EdC), que tem nos evangelhos e na doutrina social da Igreja sua principal orientação. Essas empresas estão aprendendo a valorizar as pessoas pelo que elas são e não apenas por sua utilidade econômica e estão desenvolvendo capacidade empática em suas lideranças, termo da psicologia que se refere a uma habilidade em compreender as pessoas, goste-se delas ou não. Do ponto de vista da dependência de recursos, o diferencial competitivo está nos recursos organizacionais e nos recursos humanos e não tanto nos financeiros e físicos, ou seja, tem a ver com trabalho em equipe, confiança, amizade, cooperação, capacidade de julgamento e sabedoria das pessoas.

Enquanto uma teoria de custos de transação pressupõe a busca de minimização dos custos transacionais, preocupada com diferenciação de localização, ativos fixos ou produção, as empresas de EdC desenvolvem a confiança, a solidariedade e a ética nos relacionamentos entre pessoas e empresas (Lima, 1999). Estão criando uma cultura de confiança em seus líderes, além de processos intensos de comunicação e tomada de decisão conjunta, para compartilhar informações, diminuir incertezas e a assimetria informacional. É assim que o projeto desenvolve o sentido comunitário de suas empresas.

O economista italiano Stefano Zamagni, um dos primeiros pesquisadores do projeto, afirma que os custos de transação, os de monitoração e os de confiança, inerentes a qualquer empresa são mais baixos nessas empresas (2002:11). Porque os relacionamentos internos e externos não são artificialmente construídos, mas irrompem a cada ato de gestão, sem a tentação de enganar os funcionários ou tentar extrair mais dos clientes e fornecedores. Isso reduz a necessidade de monitoramento ou gastos com propaganda. Por outro lado, quanto aos custos de juros, há convicção de que o risco de denúncias unilaterais é menor do que nas outras empresas. Zamagni conclui que essas empresas podem competir, pagando todos os impostos, evitando a corrupção ou produtos fora dos padrões socialmente responsáveis.

A pesquisa de Brandalise (2003) confirma essa competitividade, ao mostrar a estabilidade dessas empresas em termos de receita e de lucratividade, quando comparadas a outras fora do projeto. São atualmente 790 empresas espalhadas pelos cinco continentes e vêm crescendo a uma taxa líquida anual de 13\%, desde 1991, início do projeto. Há casos, no Brasil — onde são 120 empresas - com produtividade acima da média de seu setor (Gonçalves e Leitão, 2001). Três empresas estudadas por Pinto (2004) mostraram, em termos de responsabilidade social, desempenho superior às similares em ta- 
manho no banco de dados do Instituto Brasileiro de Análises Sociais e Econômicas (Ibase).

Os estudos de Gonçalves e Leitão (2001), Almeida e Leitão (2003), Pinto (2004) e Gonçalves (2005) possibilitam identificar elementos centrais na forma como se desenvolvem os relacionamentos em oito empresas ali estudadas, consideradas na vanguarda do projeto. Eles estão aqui expressos em termos de valores e práticas de gestão:

V reconhecimento de que a organização é uma construção de todos;

v não busca lucros máximos e acumulação;

v lideranças motivadas para a mudança e conscientes da necessidade do exemplo pessoal;

v elevado comprometimento com as metas e maior motivação para o trabalho;

v eliminação da mentira junto a seus stakeholders e conduta ética;

v compatibilização entre produtividade e emprego;

v participação nas decisões, diálogo, cooperação, solidariedade e espírito comunitário;

v respeito ao ambiente natural;

v espiritualidade percebida no mesmo nível da saúde física e mental.

O estudo de caso de Leitão e Kurtz (2005), em uma empresa metalúrgica de Piracicaba, concluiu que a qualidade dos seus relacionamentos interpessoais favorecia a aprendizagem de tarefas e de comportamento. Na pesquisa, com amostra superior a 50\% dos funcionários, usando análise de conteúdo, os entrevistados indicaram como propiciadores de qualidade, em ordem de importância: solidariedade, diálogo, liberdade, igualdade, compreensão, confiança, respeito, responsabilidade, amizade, honestidade, sinceridade e justiça. Os relacionamentos entre os funcionários e com a gerência aparecem em quarto lugar, entre 10 motivações possíveis para aprender, superados apenas pelo desejo de crescimento pessoal, participação nos resultados e salário (presente e futuro).

No total dos estudos realizados nessas empresas, a diferenciação nesses relacionamentos, quando comparados às empresas de orientação mais instrumental, é ponto comum. Embora ocorram diferenças entre as empresas do projeto EdC (Almeida e Leitão, 2003), particularmente entre as que come- 
çaram a operar com o início do projeto e as que já existiam antes dele e tiveram de mudar suas culturas.

A diferenciação entre as empresas do projeto está, principalmente, no maior ou menor sucesso na implantação do que denominam "cultura da partilha". E as dificuldades maiores para essa mudança cultural são decorrentes da força das contradições ideológicas existentes entre capital e trabalho e a conseqüente desconfiança secular entre patrões e empregados. As dificuldades na adesão aos novos valores estão entre os trabalhadores e entre os gerentes, principalmente nos mais experientes, aculturados em outras empresas. Habituados às práticas de controle e manipulação, a serem tratados como seres técnicos, instrumentos de trabalho, pelos donos do capital, oferecem resistência aos valores da cultura da partilha. Tais resistências diminuem à medida que percebem sinceridade nas atitudes e comportamento dos empregadores na busca por uma nova forma de relacionamento entre o capital e o trabalho.

O projeto prevê a divisão do lucro em três partes: reinvestimento no negócio, combate à pobreza e formação de um "homem novo". O último objetivo se dá por meio de palestras e encontros periódicos, onde o ideário de projeto EdC é divulgado, ou nas práticas de trabalho. Algumas empresas oferecem participação nos resultados. Mas o fato de uma parte do lucro ser destinada aos socialmente excluídos tem funcionado como elemento de integração aos valores propagados, um elemento de diferenciação para os empregados.

Depoimentos de trabalhadores demonstram a construção da confiança, entre eles: "quando a gente começa a conhecer a empresa pensa isso aí não existe!' mas na hora que a gente vai entrando, vendo que existem pessoas bem-intencionadas, que querem fazer alguma coisa, o susto acaba, o medo acaba"; ou "para mim o lucro é bem aplicado, ajuda não só a gente, ajuda outras pessoas que estão necessitadas"; ou ainda "você vê que os diretores não são consumistas, têm carros simples" (Gonçalves e Leitão, 2001).

Em suma, com ferramental de variada elaboração técnica, essas empresas estão ultrapassando os limites do instrumentalismo, ao se preocuparem mais com o humano, absorvendo a sabedoria disponível nos evangelhos e desenvolvendo um ambiente de trabalho mais de acordo com a natureza humana. O passo evolutivo está dado, essencialmente na forma como seus funcionários e gerentes se tratam. Por isso tais empresas merecem ser mais investigadas, sobretudo pelos indícios de que tais formas de relacionamento não são passíveis de instrumentalização, de serem modeladas e implantadas por apressados consultores. Há evidências de que as empresas mais avançadas no projeto comportam-se como organizações socialmente responsáveis, porque estão conseguindo lidar com um ser humano multidimensional, mais integrado ao seu ambiente organizacional e natural. 


\section{Conclusão}

As evidências quanto à importância na gestão das pessoas por meio de relacionamentos de qualidade nessas empresas são significativas. Embora o móvel psicológico de suas lideranças seja, freqüentemente, a espiritualidade cristã (nem todos os empresários são cristãos ou religiosos), é fácil perceber que algo similar ocorre em outras empresas não vinculadas a projetos dessa natureza.

Pode ser instigante ver mais de perto os microprocessos relacionais, em abordagem integrativa e interdisciplinar, com suas implicações para o conjunto das atividades dessas empresas integrantes da economia solidária e de outras eticamente orientadas. Cabe investigar até que ponto as históricas forças econômicas, sociais, políticas e ideológicas, que dominam as relações entre capital e trabalho, podem ser alteradas com base em algo aparentemente elementar, como a natureza básica das relações humanas, sejam elas explicadas pela biologia, pela doutrina cristã ou pelas visões humanistas de alguns empresários.

Como dizem Pinto e Leitão (2006:150) a experiência das empresas de EdC está trazendo à tona a submersa importância do sujeito e sua subjetividade para a prática empresarial. E também poderá trazer para a teoria.

O esquecimento da pessoa, substituída por um ente econômico e técnico, torna distorcido o conhecimento da gestão de empresas. Tal experiência está trazendo também à discussão, a dimensão transpessoal dos indivíduos pela ênfase na espiritualidade, rejeitada pela "ciência normal", e ainda incipiente em pesquisadores como Bengt Gustavsson, Imants Baruss, James Beichlere alguns outros.

A hipótese aqui levantada é que o exame das formas de relacionamentos praticadas em empresas de orientação substantiva pode apontar o que ocorre nos casos de sucessos relativos e de fracassos adiados em outras empresas, como sugerem Maturana e Bunnell (1998), que não se explicam apenas em termos de práticas financeiras e estratégias mercadológicas consideradas mal conduzidas. Estas podem estar na parte mais visível do iceberg e não mostram que a qualidade dos relacionamentos, como indutora de bem-estar, tem sua parcela de responsabilidade nos resultados operacionais.

É muito provável que a quebra do paradigma dominante e da ideologia que lhe dá sustentação, causa cognitiva da grave crise socioambiental que ameaça o planeta, também implique no reexame de questões fundamentais à existência da vida coletiva, pois como observam Nord e Fox (2004:219), parece haver crescente desconforto com os pressupostos tradicionais sobre os seres humanos nas ciências sociais. 
Faz todo sentido, portanto, o exame de projetos substantivos quando os valores do instrumentalismo dominam pessoas e organizações, com suas conseqüências para a qualidade da vida, pois qualidade de relacionamento é fator básico à qualidade de vida, em qualquer tipo de organização social. E se a promessa racionalista-modernista de progresso e bem-estar para a maioria da humanidade parece esgotada, pode ser adequado adotar abordagens que aprofundem nossa capacidade de compreender a vida associada.

\section{Referências bibliográficas}

ALBROW, M. Do organizations have feelings? Book Review, London: Routledge, 1997.

ALMEIDA, M. A.; LEITÃO, S. P. Empresas de economia de comunhão e razão substantiva. Revista de Administração Pública, v. 37, n. 6, p. 1145-1170, nov./dez. 2003.

ALVESSON, M.; DEETZ, S. Teoria crítica e abordagens pós-modernas. In: CLEGG, S.; HARDY, C.; NORD, W. R. (Eds.). Handbook de estudos organizacionais. São Paulo: Atlas, 1999.

ASHKANASY, N. M.; DAUS, C. S. Emotion in the workplace: the new challenge for managers. Academy of Management Executive, v. 16, n. 1, p. 77-86, 2002.

BEHNCKE, Rolf. Ao pé da árvore (prefácio). In: MATURANA, H.; VARELA, F. A árvore do conhecimento. São Paulo: Editorial Psy, 1995.

BRANDALISE, Luis Antonio. A finalidade do lucro para as empresas de economia de comunhão. 2003. Tese (Doutorado) — Faculdade de Economia, Administração e Contabilidade da Universidade de São Paulo.

CALAHAN, J. L. Marking the need for cultural change: the effects of emotion structuration. Organization Studies, v. 23, n. 2, p. 281-299, 2002.

CAVALLO, K. Emotional competence and leadership excellence at Johnson \& Johnson: the emotional intelligence and leadership study. Consortium for Research on Emotional Intelligence in Organizations, 2002. Disponível em: <www.eiconsortium.org/research/jj_ei_study.htm>. Acesso em: nov. de 2005.

CONRAD, C.; WHITTE, K. Is emotional expression, repression, oppression? Myths organizational affective regulation. In: DETTZ, S. A. Communication Yearbook, Thousand Oaks, CA: Sage, v. 17, p. 417-428, 1984.

FINEMAN, Stephen. A emoção e o processo de organizer. In: CLEGG, S. R.; HARD, C.; NORD, W. R. (Orgs.). Handbook de estudos organizacionais, São Paulo: Atlas, 2000. p. 157-189.

Rap Rio de Janeiro 40(5):883-907, Set./Out. 2006 
FOESTER, Hein Von. Visão e conhecimento, disfunções de segunda ordem. In: SCHINITMAN, D. F. Novos paradigmas, cultura e subjetividade. Porto Alegre: Artes Médicas, 1996.

GERALIS, M.; TERZIOUSKI, M. A quantitative analysis of the relationship between empowerment practices and service quality outcomes. Total Quality Management, v. 14, n. 1, p. 45-62, 2003.

GONÇALVES, Heloisa H. Q. A. B. A experiência dos pioneiros da economia de comunhão na liberdade no primeiro decênio (1991-2001) no Brasil. 2005. Tese (Doutorado) - Coppe/ UFRJ, Rio de Janeiro.

-; LEITÃO, S. P. Empresas de economia de comunhão: o caso Femaq. Revista de Administração Pública, v. 35, n. 6, p. 33-60, nov./dez. 2001.

HENRIQUEZ, Eugène. Os desafios éticos nas organizações modernas. Revista de Administração de Empresas, v. 37, n. 2, p. 6-17, abr./jun. 1997.

HUY, C.; LEE, C.; ROUSSEAU, D. M. Employment relationships in China: do workers relate to the organization or to people? Organization Science, v. 15, n. 2, p. 232-240, 2004.

JAHN, R. G.; DUNE, B. J. Science of the subjective. Journal of Scientific Exploration, v. 11, n. 2, p. 201-224, 1997.

KELLY, J. R.; BARSADE, S. G. Mood and emotions in small groups and work teams. Organizational Behavior and Human Decision Processes, v. 86, n. 1, p. 99-130, 2001.

LEITÃO, Sergio P. A decisão estratégica: um teste conceitual. Revista de Administração Pública, v. 37, n. 4, p. 837-858, jul./ago. 2003.

; KURTZ, R. G. M. Relacionamentos interpessoais e aprendizagem na economia de comunhão: o caso Femaq. Revista de Administração Pública, v. 38, n. 4, p. 913-938, jul./ ago. 2005.

LEVINE, J. M.; RESNICK, L. B.; HIGGINS, E. T. Social foundations of cognition. Annual Review of Psychology, v. 44, p. 585-612, 1993.

LIMA, Maria Aparecida B. Economia de comunhão X custos de transação: uma visão das organizações imbuídas da cultura da partilha. Revista Eletrônica de Administração REAd/UFRGS, ed. 12, v. 5, n. 4, nov./dez. 1999.

LUCAS, R. E.; DIENER, E.; SUH, E. Discriminant validity of well-being measures. Journal of Personality and Social Psychology, v. 71, n. 3, p. 616-628, 1996.

MAANEN, Van; KUNDA, G. Real feelings, emotional expression and organizational culture. In: CUMMINGS, L.; STAW, B. M. (Eds.). Research in organizational behavior, Greenwich, CT: JAI, v. 6, p. 287-365, 1989. 
MACHADO, Ana Cláudia M. Economia de comunhão: elementos para uma teoria organizacional. 2006. Tese (Doutorado) — Departamento de Engenharia Industrial da PUC-Rio.

MATURANA, Humberto. La realidad: objetiva o construída. Guadalajara: Editorial Anthropus, 1995.

- Emoções e linguagem na educação e na política. Belo Horizonte: UFMG, 2001.

; BUNNELL, P. Biosphere, homosphere and robosphere: what has to do with business? Society for Organizational, Learning Member's Meeting. Mherst, M.A. June 1998. Disponível em:<www.solonline.org/res/wp/maturana/indez.html>. Acesso em: mar. 2004.

; VARELA, F. A árvore do conhecimento. São Paulo: Editorial Psy, 1995.

MAYER, J. D.; CARUSO, D. R.; SALOVEY, P. Emotional intelligence meets traditional standards for an intelligence, v. 27, n. 4, p. 267-298, 1999.

MORIN, Edgar. O método 3. O conhecimento do conhecimento. Porto Alegre: Sulina, 1999.

Ciência com consciência. Rio de Janeiro: Bertrand Brasil, 2003

MOTTA, Fernando C. P. Teoria das organizações. São Paulo: Pioneira, 1986.

MUMBY, D. K.; PUTNAM, L. The politcs of emotion: a feminist reading of bounded rationality. Academy of Management Review, v. 17, p. 465-486, 1992.

NORD, W. R.; FOX, S. O indivíduo nos estudos organizacionais: o grande ato de desaparecimento? In: CLEGG, S. R.; HARDY, C.; NORD, W. R. (Orgs.). Handbook de estudos organizacionais, São Paulo: Atlas, 2004. v. 3, p. 186-225.

OFFERMAN, L. R. et al. The relative contribution of emotional competence and cognitive ability to individual and team performance. Human Performance, v. 17, p. 219-243, 2004.

PINTO, Mario C. S. A economia de comunhão sob o olhar da teoria dos stakeholders. 2004. Tese (Doutorado) - Departamento de Administração de Empresas da PUC — Rio de Janeiro, 2004.

; LEITÃO, S. P. Economia de comunhão: empresas para um capitalismo transformado. Rio de Janeiro: FGV, 2006.

POLANYI, Karl. A grande transformação. São Paulo: Campus, 2000.

RAFAELI, A.; SUTTON, R. Expression of emotion as part of the work role. Academy of Management Review, v. 12, n. 1, p. 23-37, 1987.

RAMOS, A. G. A nova ciência da organização. Rio de Janeiro: FGV, 1981.

REJUN, Q.; ZIGANG, Z. Work group in emotions in Chinese culture settings. Singapore Management Review, v. 27, n. 1, p. 70-86, 2005.

Rap Rio de Janeiro 40(5):883-907, Set./Out. 2006 
TENBRUNSEL, A. E. et al. Cognições em organizações. In: CLEGG, S. R.; HARDY, C.; NORD, W. R. (Orgs.). Handbook de estudos organizacionais, São Paulo: Atlas, 2004. v. 3, p. 33-68.

VARELA, F.; SHEAR, J. First-person accounts: why, what and how. In: (Eds.). The view from within. First-person approaches to the study of consciousness. U.K: Imprint Academic, 2002.

WILSON, M. G. et al. Work characteristics and employee health and well-being: test of a model of healty work organization. Journal of Occupational and Organizational Psychology, v. 77, n. 4, p. 565-588, 2004.

WEISS, H. M. Desconstructing job satisfaction separating evoluations, beliefs and affective experiences. Human Resource Management Review, v. 12, p. 173-194, 2002.

WONG, C.; LAW, K. S. The effects of leader and follower emotional intelligence on performance and attitude: an exploratory study. The Leadership Quarterly, v. 13, p. 243-274, 2002.

ZAMAGNI, Stefano. Fundamento e significado da experiência da economia de comunhão. In: BRUNI, L. (Org.). Economia de comunhão. Vargem Grande Paulista, São Paulo: Cidade Nova, 2002. 